\title{
Public Health Law: Power, Duty, Restraint Revised AND ExPANDEd SECond Edition
}

\author{
Lawrence O. Gostin, University of California Press \\ Milbank Books on Health and the Public, 2008
}

Breno Rego Pinto Rodrigues da Costa ${ }^{(8)}$

Abordar a relação entre Direito e Saúde para os alunos dos primeiros anos da graduação em Direito implica quase que necessariamente despertar a curiosidade acerca de dois assuntos: novas questões impostas por novas tecnologias e relação médico-paciente. Terapia genética, células estaminais, técnicas reprodutivas, clonagem etc. são assuntos que permeiam constantemente as páginas dos jornais e noticiários da televisão, gerando a expectativa de que os principais tópicos de discussão nas salas de aula e meios científicos acompanhem a tendência da mídia geral. Por seu turno, a relação entre o médico e o seu paciente levanta questões de responsabilidade civil e direitos contratuais mais facilmente identificáveis com a impressão geral que se tem do papel dos profissionais do direito.

Ao lançar a segunda edição do seu "Public Health Law - Power, Duty, Restraint", Lawrence Gostin mostra mais uma vez o quanto as primeiras impressões podem ser enganadoras. Nem sempre os problemas que recebem maior atenção são, de fato, os de maior relevância ou interesse prático. Abordando questões envolvendo o direito e a saúde pública, o autor envolve o leitor em temas de altíssima indagação e relevância para o estudo do direito e das liberdades públicas em geral.

A medicina individual, enquanto ciência e prática, responde por apenas uma pequena parte dos cuidados necessários à manutenção de uma população saudável. A maior parte do projeto de elevação da qualidade de vida de uma comunidade é levada a cabo pela saúde pública, cuja orientação para o coletivo garante a priorização de medidas que levam em conta outros fatores, como a efetividade em termos de custos sociais. Ao destacar

(*) Mestre em Ciências Jurídico-Políticas pela Faculdade de Direito da Universidade de Coimbra. E-mail: <brenorodriguesdacosta@gmail.com>. Recebido em 02.02.09. 
tais questões no âmbito do direito sanitário, o autor afirma definitivamente a autonomia do direito da saúde pública, enquanto sistema normativo voltado para a regulação de situações que, por sua natureza, não devem ser tratadas de maneira similar aos tradicionais problemas envolvendo a medicina individual. Por outro lado, demonstra a utilidade e importância do direito enquanto ferramenta de implementação de políticas de saúde pública, além da sua função de garantir os interesses individuais quando estão em jogo medidas de proteção da saúde pública.

Public Health Law revela uma preocupação não apenas com o tratamento claro e tecnicamente apurado dos temas da saúde pública, mas procura também servir como veículo de divulgação da própria existência e importância de muitos destes problemas, largamente ignorados, enquanto tais, pela academia e pelo público em geral.

A obra é dividida em quatro partes. A primeira é dedicada aos fundamentos conceituais do Direito da saúde pública. Ali o autor define o que entende por saúde pública e identifica, de um modo geral, características das normas e estatutos que regem o direito da saúde pública. Nesta primeira parte, já é permitido ao leitor observar as enormes distinções entre a regulação da saúde pública e aquela dedicada à medicina individual. Os valores envolvidos determinam diferentes testes aplicáveis às normas para aferir a sua legitimidade e validade em face do sistema jurídico.

A segunda parte dedica-se a um estudo mais concreto da estrutura normativa que envolve a saúde pública da perspectiva do direito norte-americano. A saúde pública pode ser visualizada por diversos ângulos jurídicos, e Gostin apresenta algumas possibilidades, mostrando visões desde o direito constitucional até o direito internacional, passando pela disciplina da responsabilidade civil e do direito administrativo. Deste modo, permite ao leitor uma percepção abrangente da variedade de normas jurídicas convocáveis quando se lida com a saúde da população.

A terceira parte trata de questões concretas, algumas das que surgem da necessidade de proteção e elevação do nível de saúde de uma população. Aqui, o autor trata do problema da informação em saúde, tanto do ponto de vista da vigilância estatal sobre os indivíduos como relativamente à comunicação de massas, tanto governamental como privada. Trata também especificamente das medidas de combate a epidemias e das suas consequências em matéria de direitos individuais e liberdades públicas.

Um capítulo conclusivo dedicado ao futuro da saúde pública e da sua disciplina jurídica fecha a obra, trazendo reflexões sobre a política e economia envolvendo a saúde pública, bem como novos limites normativos para os poderes do estado. Merece atenção neste capítulo o estudo de caso envolvendo obesidade e doenças crônicas e a limitação de poderes na saúde pública. Com efeito, a questão dos limites da interferência do Estado no 
estilo de vida das pessoas é uma questão que vai se tornando mais evidente à medida que a avaliação pública destas interferências deixa a zona da quase unanimidade e passa a tocar as terminações sensíveis da liberdade individual.

O tema da paradoxal oposição eventual entre interesses coletivos e individuais, públicos e privados, no campo da saúde pública é a linha condutora da obra, aparecendo em diversos momentos ao longo do texto. A saúde pública se revela um campo privilegiado de interações entre estes interesses conflitantes, propício, portanto, a servir como pano de fundo para um estudo sobre a liberdade e os limites do poder do Estado. A intenção declarada do autor é analisar situações em que ocorrem permutas, compromissos (trade-offs, na expressão original) entre interesses e direitos individuais e coletivos. Tal preocupação é extremada nos casos em que as medidas necessárias à proteção da saúde pública envolvem coerção pessoal, seja ela direta ou indireta.

Voltada a um público interdisciplinar, a obra procura não utilizar exclusiva e detalhadamente o vocabulário jurídico. A execução é irrepreensível, sem a costumeira prolixidade dos meios jurídicos, mas sem perder em profundidade. Os tópicos são compreensivos, e os temas são abordados com elementos históricos e uma análise pormenorizada dos conceitos, teorias e casos práticos. O pragmatismo característico da doutrina jurídica norteamericana está representado pela extensiva utilização da análise de dados e decisões judiciais como critério de validação de alguns pontos de vista, mas o autor não se deixa simplesmente levar pelas opiniões dominantes, refletindo sempre com lógica e sensibilidade sobre os argumentos em jogo.

Além do corpo de texto principal, a obra inclui caixas de texto com dados e destaques, reprodução de fotografias, cartuns e citações, úteis para ilustrar as concepções sobre a saúde pública e as medidas do Estado voltadas à sua garantia. Especialmente em relação à compreensão histórica da percepção pública dos problemas de saúde, estes elementos textuais são reveladores. Cada capítulo recebe um conjunto de notas concentradas no final do texto; estas incluem as indicações bibliográficas citadas e um acervo de casos ainda impensável na jurisprudência brasileira. Há, ainda, uma útil lista de bibliografia selecionada dividida por assunto.

O autor escreve com fluidez e segurança sobre os diversos temas que compõem o estudo. A leitura do capítulo dedicado à teorização do direito da saúde pública é tão prazerosa como a dos capítulos dedicados à obesidade ou vacinação. A linguagem é acessível tanto para estudantes de direito quanto de saúde pública, com apenas alguns ocasionais desvios para o jurídico, quando necessário, e isso torna a obra uma leitura instrutiva e agradável.

Apesar de tratar-se de uma obra jurídica estrangeira, ainda mais de uma obra vinda de um país da tradição da common law, o livro de Lawrence 
Gostin apresenta casos e soluções jurídicas que, na sua maior parte, podem encontrar aplicação quase que direta no sistema jurídico brasileiro. Isto ocorre porque a maior parte da argumentação gira em torno de direitos e liberdades públicas de matriz constitucional, permitindo aos intérpretes a utilização de mecanismos de harmonização do sistema muito semelhantes em ambos os sistemas jurídicos. Tenha-se como exemplo os testes a que são submetidas as intenções regulatórias dos legisladores americanos e brasileiros: princípios como o da igualdade e da proporcionalidade, bem como a maioria dos direitos individuais, possuem configurações normativas muito semelhantes, abrindo a possibilidade de aproveitamento recíproco das experiências regulatórias na elaboração dos testes de legitimidade.

De um modo geral, Public Health Law pode ser considerado uma leitura obrigatória tanto para aqueles que desejam iniciar-se no universo do direito da saúde pública quanto para quem queira aprofundar-se nos temas propostos, sendo um livro de primeira linha, que revela o "estado da arte" da área. Certamente, é uma obra que merece a atenção dos brasileiros e até mesmo uma tradução, pois, suas conclusões não se restringem exclusivamente ao direito norte-americano. 